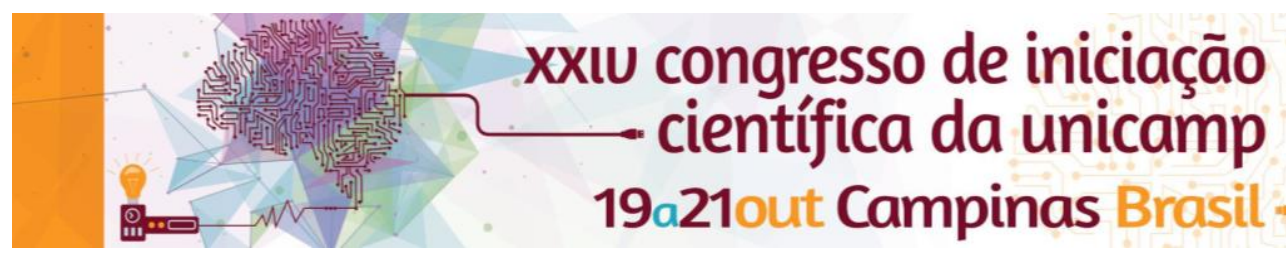

\title{
Investigação experimental da resistência e comportamento de ligações metálicas submetidas a esforços cisalhantes sob altas temperaturas
}

\section{Daniela Araújo Alves, Rafaela Matiazzo Peixoto, Luiz Carlos Marcos Vieira Jr.}

\section{Resumo}

Neste trabalho foi investigado o comportamento de ligações metálicas parafusadas por meio de ensaios com três diferentes diâmetros de parafusos de alta resistência ASTM A325 e A490 e um sistema de carregamento com dois planos de cisalhamento, ensaiados a temperatura ambiente e a $200^{\circ} \mathrm{C}, 400^{\circ} \mathrm{C}, 500^{\circ} \mathrm{C}$ e $600^{\circ} \mathrm{C}$, de forma a verificar a resistência ao cisalhamento desses parafusos e mensurar os efeitos de altas temperatura sobre essa propriedade.

\section{Palavras-chave:}

Parafusos, cisalhamento, alta temperatura.

\section{Introdução}

As propriedades do material aço dependem da sua estrutura cristalina e composição química, as quais sofrem modificações mediante variações térmicas $e$ resultam em alterações de suas propriedades mecânicas ${ }^{1}$. As ligações parafusadas, por sua vez, estão sujeitas a diferentes formas de ruína, dentre as quais pode-se ressaltar a ruptura por cisalhamento. As normas de dimensionamento de estruturas metálicas apenas apresentam um método prescritivo, baseado em tabelas geradas a partir de ensaios laboratoriais com detalhamentos conhecidos e padronizados, para o dimensionamento de ligações metálicas sob altas temperaturas.

\section{Resultados e Discussão}

Diante disso, o estudo em questão se propôs a estudar o modelo de uma ligação essencialmente solicitada à cisalhamento sob altas temperaturas, no qual parafusos comuns e de alta resistência (ASTM A325 e A490) com diâmetro de $19 \mathrm{~mm}, 22 \mathrm{~mm}$ e $25 \mathrm{~mm}$ foram submetidos a um carregamento com dois planos de cisalhamento (Figura 1) e ensaiados segundo a metodologia denominada como campo térmico estacionário à temperatura ambiente, $200^{\circ} \mathrm{C}, 400^{\circ} \mathrm{C}, 500^{\circ} \mathrm{C}$ e a $600^{\circ} \mathrm{C}$.

Figura 1. Sistema de carregamento e forno utilizados
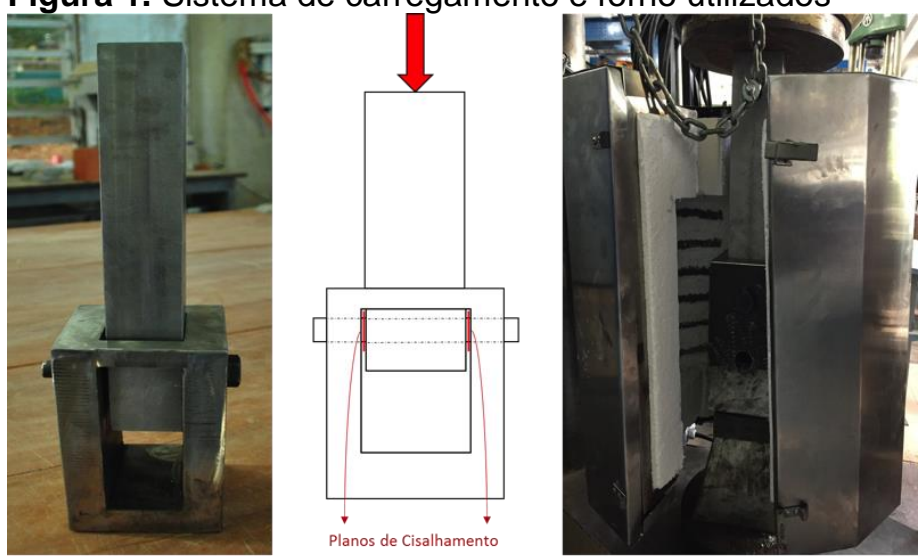

Os parafusos ensaiados foram levados até a ruptura e a partir das leituras do carregamento de compressão e deslocamento vertical, foram traçados gráficos como mostrado na Figura 2.

DOI: 10.19146/pibic-2016-51230
Figura 2. Gráficos força $x$ deslocamento para os parafusos ASTM A325 com 19mm de diâmetro.

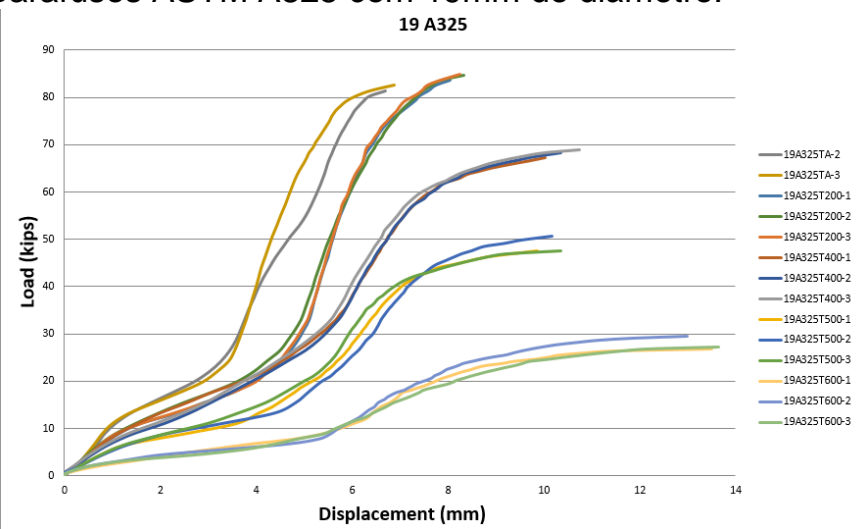

Também foram registradas por fotografia as seções dos parafusos rompidos, a fim de analisar o modo de ruptura, possíveis modificações da textura e cor do material e deformações plásticas.

Verificou-se que tanto para os parafusos A325 como para os A490, houve um ganho sensível de ductilidade a $200^{\circ} \mathrm{C}$ em relação aos ensaios a $25^{\circ} \mathrm{C}$, mas a resistência não se alterou. Nos ensaios a $400^{\circ} \mathrm{C}$ em diante, verificou-se uma perda bastante expressiva de resistência, acompanhada de uma ductilidade muito maior em relação aos ensaios a temperaturas inferiores.

\section{Conclusões}

É possível dividir os resultados em duas faixas de resposta aos efeitos térmicos: de 25 a $200^{\circ} \mathrm{C}$, na qual o material mantém a sua resistência ao esforço aplicado, enquanto que na faixa acima de $400^{\circ} \mathrm{C}$, a resistência cai de forma aproximadamente linear, acompanhada de ductilidade expressivamente maior.

\section{Agradecimentos}

CNPq - Conselho Nacional de Desenvolvimento Científico e Tecnológico

NIST - National Institute of Standards and Technology

\footnotetext{
${ }^{1}$ Liang Yu, B.S.; "Behavior of Bolted Connections During and After a Fire", 196, Dissertação, University of Texas at Austin, 2006.
} 